\title{
Homo- and Copolymerizations of (Meth)Acrylates with Olefins (Styrene, Ethylene) Using Neutral Nickel Complexes: A Dual Radical/Catalytic Pathway
}

\author{
Alexandra Leblanc, Etienne Grau, Jean-Pierre Broyer, Christophe Boisson, Roger Spitz, and Vincent Monteil* \\ Universite de Lyon, Univ. Lyon 1, CPE Lyon, CNRS UMR 5265 Laboratoire de Chimie Catalyse Polymeres et \\ Procedes (C2P2), LCPP team Bat 308F, 43 Bd du 11 novembre 1918, F-69616 Villeurbanne, France
}

\begin{abstract}
Nickel complexes $\left[(\mathrm{X}, \mathrm{O}) \mathrm{NiR}\left(\mathrm{PPh}_{3}\right)\right](\mathrm{X}=\mathrm{N}$ or $\mathrm{P})$, designed for the polymerization of ethylene, were found to be efficient for the homo- and copolymerization of butylacrylate (BuA), methylmethacrylate (MMA), and styrene. Their role as a radical initiator was demonstrated from the calculation of the copolymerization reactivity ratios. It was shown that the effi-ciency of the radical initiation is improved by the addition of $\mathrm{PPh}_{3}$ to the nickel complexes as well as by increasing the temperature. The dual role of a nickel complex as radical initiator and catalyst was exploited to succeed in the copolymerization of ethylene with BuA and MMA. Multiblock copolymers containing sequences of both ethylene and polar monomers were thus prepared for the first time by a dual radical/catalytic mechanism.
\end{abstract}

\section{Introduction:}

Polar vinyl monomers such as (meth)acrylates are classically homopolymerized by anionic(1) or radical(2) mechanisms: both can be metal-mediated. Transition metal (TM)-based polymerizations involving coordination of the monomer have been investigated for the homopolymerizations of polar vinyl monomers. This topic, reviewed recently by Chen,(3) actually covers two very different polymerization mechanisms according to Chen definitions: migratory insertion (Cossee mechanism) and coordinative-anionic addition (anionic polymerization). On one hand, the early TM-based homopolymerization of polar vinyl monomers such as (meth)acrylates did not proceed via migratory insertion in a carbon-metal bond but via a coordinative-anionic mechanism involving an oxygen-metal bond with metal enolate intermediates. (3) From the pioneering works of Yasuda(4) with lanthanide-based complexes and Collins(5) with group 4 metallocenes, the homopolymerization of (meth)acrylates was developed with high degrees of control over the living character and the stereochemistry of the polymerization.(3) On the other hand, the late TM-based polymerization of polar vinyl monomers may proceed via a migratory insertion mechanism. A great number of metal complexes of iron, $(6)$ nickel,(79) palladium,(10) and copper(11) were reported to homopolymerize (meth)acrylates in the presence of a large excess of MAO as the activator (or in the case of palladium-based systems without additional MAO). However, in most cases, it is still not clear whether the mechanism of polymerization is based on migratory insertion or free radical or ionic polymerization. In some cases, it has been clearly demonstrated that a free radical mechanism is involved, $(9 b, 10)$ whereas in other cases, polymerization was induced by the cocatalyst (MAO) itself.(12) In the case of palladium complexes, it is assumed that the homolytic cleavage of the carbon-metal bond generates radicals that are able to homopolymerize (meth)acrylates via a free radical mechanism. (10) Even though examples of pure migratory insertion-based homopolymerization of polar vinyl monomers are scarce, $(13)$ consecutive units of polar vinyl monomers were observed in copolymers with nonpolar olefins such as ethylene. $(3,14)$

In the present work, we investigated the behavior of neutral nickel complexes $\left[(X, O) N i R\left(P P h_{3}\right)\right](X=N$ or $P)$ in the homo- and copolymerization of (meth)acrylates (in the absence of cocatalysts such as MAO). These catalysts were initially designed for the polymerization of nonpolar olefins and used in the presence of phosphine scavengers to allow the coordination of the olefin. It has been shown that the addition of phosphine to the polymerization of ethylene with these nickel catalysts leads to the deactivation of the catalyst.(15c) Countercurrent of this "classical" mechanism for olefin polymerization, we present evidence that the addition of triphenylphosphine to the nickel complexes leads to a drastic increase in activity for the polymerization of 
(meth)acrylates. The rationalization of this unexpected effect is discussed in this Article; as a result, new routes for the copolymerization of ethylene and (meth)acrylates are described.

\section{Experimental Section:}

All chemicals were handled under an argon atmosphere using standard Schlenk techniques. Ethylene (purity 99.95\%) was purchased from Air Liquide and used without any further purification. MMA, BuA, and styrene were purchased from Acros, dried over $\mathrm{CaH}_{2}$, and distilled under partial pressure of argon. $\mathrm{PPh}_{3}$ and the nickel precursors were purchased from Aldrich and used without further purification.

The salicylaldimine ligand was obtained by condensation of 2,6-diisopropylaniline with 3,5-iodosalicylaldehyde. Complex 1 was obtained by reaction of the sodium salt of the ligand with trans-( $\left.\mathrm{PPh}_{3}\right)_{2} \mathrm{NiPhCl}(16)$ in toluene according to a literature procedure.(15b, 17a) An orange powder was obtained (yield $45 \%)$. ${ }^{1} \mathrm{H}$ NMR (benzene$\left.d_{6}\right): \delta 8.2(\mathrm{~d}, \mathrm{CH}=\mathrm{N}, 1 \mathrm{H}), 6.3-7.2\left(\mathrm{~m}, \mathrm{H}_{\text {arom }}, 25 \mathrm{H}\right), 4.0(\mathrm{~m}, \mathrm{CHMe} 2,2 \mathrm{H}), 1.2(\mathrm{~d}, \mathrm{CHMe} 2,6 \mathrm{H}), 1.1(\mathrm{~d}, \mathrm{CHMe} 2,6 \mathrm{H}) .{ }^{13} \mathrm{C}$ NMR (benzene- $\left.d_{6}\right)$ : $\delta 165.8(C-O), 163.5(C=N), 150.5\left(\right.$ Carom), $149.9\left(C_{\text {arom }}-N\right), 142.6\left(C_{\text {arom }}\right), 140.8$ (Carom), 137.7 (o-C of Ni-Ph), 135.3 (o-C of Ni-PPh 3 ), 132.9 (i-C of Ni-Ph), 132.1-131.5 (i-C of Ni-PPh 3 ), 130.5 (p-C of Ni-PPh 3 ), 127.7 (m-C of Ni-PPh 3 ), 126.8 (p-C of Ni-Ph), 125.9 ( $\left.\mathrm{C}_{\text {arom }}\right), 123.4$ ( $\left.\mathrm{C}_{\text {arom }}\right), 122.1$ ( $\left.\mathrm{C}_{\text {arom }}\right), 121.0(\mathrm{~m}-\mathrm{C}$ of Ni-Ph), 97.6

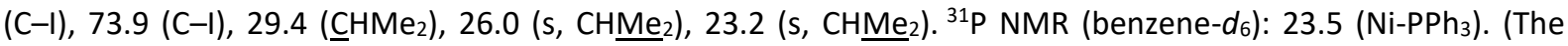
absence of the signal of free $\mathrm{PPh}_{3}$ at $-5 \mathrm{ppm}$ was systematically checked.)

The phosphinoenolate ligand was obtained from the deprotonation of (ethoxycarbonyl methyl)triphenylphosphonium bromide by a weak base such as triethylamine, followed by the addition of benzoylchloride.(18) Complex $\mathbf{2}$ was obtained by the oxidative addition of the ligand to a zerovalent nickel complex $\mathrm{Ni}(\mathrm{COD})_{2}$, leading to an alkylated metal complex by transfer of a phenyl group from the phosphorus to the nickel.(19a, 19e) The complex is stabilized by the presence of a coordinated triphenylphosphine molecule. A yellow solid was obtained (yield 60\%). ${ }^{1} \mathrm{H}$ NMR (chloroform- $d$ ): $\delta 8.20-6.14(\mathrm{~m}, \mathrm{Harom}, 35 \mathrm{H}), 3.8\left(\mathrm{q}, \mathrm{O}-\mathrm{CH}_{2} \mathrm{CH}_{3}\right.$, $2 \mathrm{H}), 0.6\left(\mathrm{t}, \mathrm{O}-\mathrm{CH}_{2}-\mathrm{CH}_{3}, 3 \mathrm{H}\right) .{ }^{13} \mathrm{C} \mathrm{NMR}$ (chloroform-d): $\delta 165.4(\mathrm{C}=\mathrm{O}), 134.3,133.6,133.5,131.3,129.7-129.3$, $129.0,127.8,126.7,126.0,121.2,91.0,58.3\left(\mathrm{O}-\mathrm{CH}_{2}-\mathrm{CH}_{3}\right), 13.8\left(\mathrm{O}-\mathrm{CH}_{2}-\underline{\mathrm{C}} \mathrm{H}_{3}\right)$.

\section{Homopolymerization of MMA, BuA, or Styrene}

In a Schlenk tube, the desired amount of complex $\mathbf{1}$ or $\mathbf{2}$ was dissolved in the monomer ( $50 \mathrm{~mL})$. The mixture was heated to the desired temperature under magnetic stirring. During the polymerization, samples were regularly collected to determine the yield of the reaction by gravimetry and thus its kinetic profile.

\section{Copolymerizations of MMA, BuA, and Styrene}

The same procedure as that for the homopolymerizations was followed with a total volume of monomers of 10 $\mathrm{mL}$. Several mixtures of the two corresponding monomers $A$ and $B$ were investigated: $A / B(w t \%)=20 / 80,40 / 60$, $50 / 50,60 / 40,70 / 30,80 / 20$. At the end of the polymerization, the mixture was cooled and the reaction was quenched by the addition of acidic ethanol.

\section{Copolymerizations of Ethylene and MMA or BUA}

Caution: these polymerizations involve high pressure and explosive gas. Ethylene copolymerizations were performed in a $160 \mathrm{~mL}$ stainless steel autoclave (equipped with safety valves, stirrer, oven) from Parr Instrument. High-pressure ethylene was stored in a $1.5 \mathrm{~L} \mathrm{intermediate} \mathrm{tank.} \mathrm{The} \mathrm{tank} \mathrm{was} \mathrm{cooled} \mathrm{to}-20^{\circ} \mathrm{C}$ to liquefy ethylene at 35 bar. When the thermodynamic equilibrium was reached, the intermediate tank was isolated and heated to reach an ethylene pressure of 150 bar. This tank was used to fill in the reactor and maintain a constant ethylene pressure during the reaction. The nickel complex and triphenylphosphine were dissolved in $50 \mathrm{~mL}$ of MMA or BuA in a Schlenk tube, then introduced to the reactor by cannulation. The stirred reactor $(250 \mathrm{rpm})$ was then pressurized with ethylene, and the reaction mixture was heated to the desired temperature. The pressure was adjusted to the desired value. At the end of the polymerization, the reactor was slowly cooled and degassed. Polymer was then isolated by evaporation of the polymerization medium and was then dried under vacuum at $70^{\circ} \mathrm{C}$. 
Copolymers ( $1 \mathrm{~g}$ ) were extracted in a Kumagawa apparatus for $2 \mathrm{~h}$ in boiling methylethylketone (MEK) $\left(80^{\circ} \mathrm{C}\right)$. Two fractions were collected: the fraction soluble in boiling MEK (after evaporation of MEK and drying) and the insoluble fraction (after drying).

\section{Polymer Analysis}

The molecular weights of the homo- and copolymers of MMA, BuA, and styrene were determined by size exclusion chromatography (SEC) using a WATERS 717 injector and four columns (one precolumn PLgel Olexis guard and three columns PLgel $5 \mu \mathrm{m}$ Mixed C) at $30^{\circ} \mathrm{C}$ in THF (flow rate: $1 \mathrm{~mL} / \mathrm{min}$ ). Two detectors were used (light scattering and refractometer) to obtain the absolute values of molecular weight. The molecular weights of the ethylene-containing polymers (copolymers of ethylene and MMA or BuA and homopolyethylenes) were determined by size exclusion chromatography (SEC) using a Waters Alliance GPCV 2000 instrument (columns: PLgel Olexis) with two detectors (viscosimeter and refractometer) at $150{ }^{\circ} \mathrm{C}$ in trichlorobenzene (flow rate: 1 $\mathrm{mL} / \mathrm{min}$ ). The system was calibrated with polystyrene standards using universal calibration.

The thermal properties of the ethylene-MMA or ethylene-BuA copolymers or homopolyethylenes were determined by differential scanning calorimetry (DSC) on a Setaram DSC 131 apparatus at a heating rate of 5 or $10 \mathrm{~K} / \mathrm{min}$ from -100 to $20^{\circ} \mathrm{C}$ and from 20 to $150^{\circ} \mathrm{C}$. The samples were heated and cooled twice, and the reported data were obtained during the second heating.

The chemical composition and tacticity of the polymers were determined by high-resolution liquid nuclear magnetic resonance (NMR) spectroscopy. The analyses were carried out on a Bruker DRX 400 spectrometer operating at $400 \mathrm{MHz}$ for ${ }^{1} \mathrm{H}$ and at $100.6 \mathrm{MHz}$ for ${ }^{13} \mathrm{C}$ at the "Service commun de RMN des Polymères - Institut de Chimie de Lyon" in Villeurbanne. Spectra were obtained with a $5 \mathrm{~mm}$ QNP probe.

The homo- and copolymers of MMA, BuA, and styrene were examined as 10-15\% (w/v) solutions in chloroform$d_{1}$ at $323 \mathrm{~K}$. The chemical shift values $(\delta)$ are given in $\mathrm{ppm}$ with reference to the internal standard tetramethylsilane (TMS). The tacticty of the MMA homopolymers was determined from the $\mathrm{CH}_{3}$ signal at 0.7 to $1.3 \mathrm{ppm}\left({ }^{1} \mathrm{H}\right.$ NMR). The composition of the copolymers was determined by ${ }^{1} \mathrm{H}$ NMR using signals at: (1) 0.5 to 1.3 ppm for MMA $\left(\mathrm{CH}_{3}\right)$, at 3.5 to $4.0 \mathrm{ppm}$ for $\mathrm{BuA}\left(\mathrm{O}-\mathrm{CH}_{2}\right)$, and at 6.5 to $7.5 \mathrm{ppm}$ for styrene $\left(\mathrm{H}_{\text {arom }}\right)$ in the case of styrene/BuA and styrene/MMA copolymers and (2) at $3.6 \mathrm{ppm}$ for MMA (O- $\left.\mathrm{CH}_{3}\right)$ and at $4.0 \mathrm{ppm}$ for BuA (O$\mathrm{CH}_{2}$ ) in the case of BuA/MMA copolymer.

The copolymers of ethylene and MMA or BuA (and homopolyethylenes) were examined as $10-15 \%$ (w/v) solutions using a mixture of tetrachloroethylene (TCE) and benzene- $d_{6}(2 / 1 \mathrm{v} / \mathrm{v})$ at $363 \mathrm{~K}$. The chemical shift values $(\delta)$ are given in ppm with reference to the internal standard TMS for ${ }^{1} \mathrm{H} N M R$ and to the $\left(-\left(\mathrm{CH}_{2}\right)_{n^{-}}\right)$signals of polyethylene at $30.00 \mathrm{ppm}$ for ${ }^{13} \mathrm{C}$ NMR. The composition of the copolymers was determined by ${ }^{1} \mathrm{H}$ NMR. For $\mathrm{E} / \mathrm{MMA}$ copolymers: $\% \mathrm{MMA}=100 /(1+((A-5) / 4))$, where $A$ is the integral of the signals between 1 and $2.5 \mathrm{ppm}$ and the integral of $\mathrm{O}-\mathrm{CH}_{3}$ signal at $3.6 \mathrm{ppm}$ calibrated at 3. For $\mathrm{E} / \mathrm{BuA}$ copolymers: $\% \mathrm{BuA}=100 /(1+((A-10) / 4))$, where $A$ is the integral of the signals between 1 and $2.5 \mathrm{ppm}$ and the integral of $\mathrm{O}-\mathrm{CH}_{2}$ signal at 4 ppm calibrated at 2.

\section{Results and Discussion}

Homo- and copolymerizations of meth(acrylates) and styrene were investigated using two neutral square planar nickel complexes: the nickel(II) salicylaldiminato complex $\mathbf{1}$ and the nickel(II) phosphinoenolate complex 2.
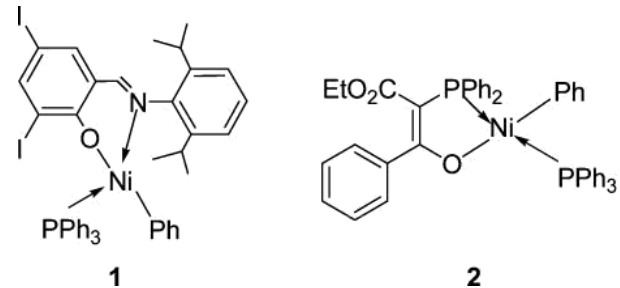

These nickel complexes were developed for the oligo-/polymerization of ethylene in organic(15, 19) and aqueous dispersed media.(17) These systems generally require the presence of a phosphine scavenger to activate the polymerization by providing a vacant site for the olefin coordination. Moreover, such complexes and especially nickel(II) salicylaldiminato complexes have been reported as inefficient catalysts for the homopolymerization of (meth)acrylates, $(20)$ as well as for the copolymerization of ethylene and 
(meth)acrylates $(14 d)$ in the absence of additional cocatalysts such as MAO. $(3,8)$ In the present work, complexes $\mathbf{1}$ and $\mathbf{2}$ were used without phosphine scavenger and without any aluminum-based cocatalysts.

\section{Homopolymerizations of Methyl Methacrylate and Butylacrylate}

The homopolymerization of methyl methacrylate (MMA) was investigated using complex 1 in bulk at temperatures from 25 to $70^{\circ} \mathrm{C}\left([\mathrm{Ni}]=2.3 \mathrm{mmol} \cdot \mathrm{L}^{-1}\right.$ and $\left.[\mathrm{MMA}]=9.3 \mathrm{~mol} \cdot \mathrm{L}^{-1}\right)$. Under these conditions $\mathrm{MMA}$ does not polymerize by thermal self-initiation in the absence of the nickel complex. In the presence of complex 1, polymerization occurred, but the polymer yields remained very low (up to $2 \%$ after $20 \mathrm{~h}$ at $70{ }^{\circ} \mathrm{C}$ ). A high-molecular-weight, moderately syndiotactic poly(methylmethacrylates) (PMMA) was produced $\left(M_{n}=(3\right.$ to 4) $\times 10^{5} \mathrm{~g} / \mathrm{mol}, \mathrm{PDI}=3$ to $\left.4 ; \% \mathrm{rr}=70 \%\right)$.

When triphenylphosphine was added to $1\left(\mathrm{PPh}_{3} / \mathbf{1}: 3 / 1\right)$, the formation of PMMA was much more efficient (Figure 1). This was completely unexpected for a "classical" olefin polymerization system: phosphine scavengers are indeed usually used to activate neutral nickel complexes.

Under these polymerization conditions, $\mathrm{PPh}_{3}$ alone is not able to initiate the polymerization of MMA. With the combination 1/PPh $\mathrm{Ph}_{3}$, the PMMA conversions achieved after $2 \mathrm{~h}$ were $\sim 5 \%$ at $25{ }^{\circ} \mathrm{C}, \sim 10 \%$ at $50{ }^{\circ} \mathrm{C}$, and $\sim 30 \%$ at $70^{\circ} \mathrm{C}$ and the initial slopes of the kinetic profiles increased with increasing temperature (Figure 1 ). Upon doubling the nickel concentration, the initial slope became steeper, and high PMMA yields (up to 50\%) were obtained.

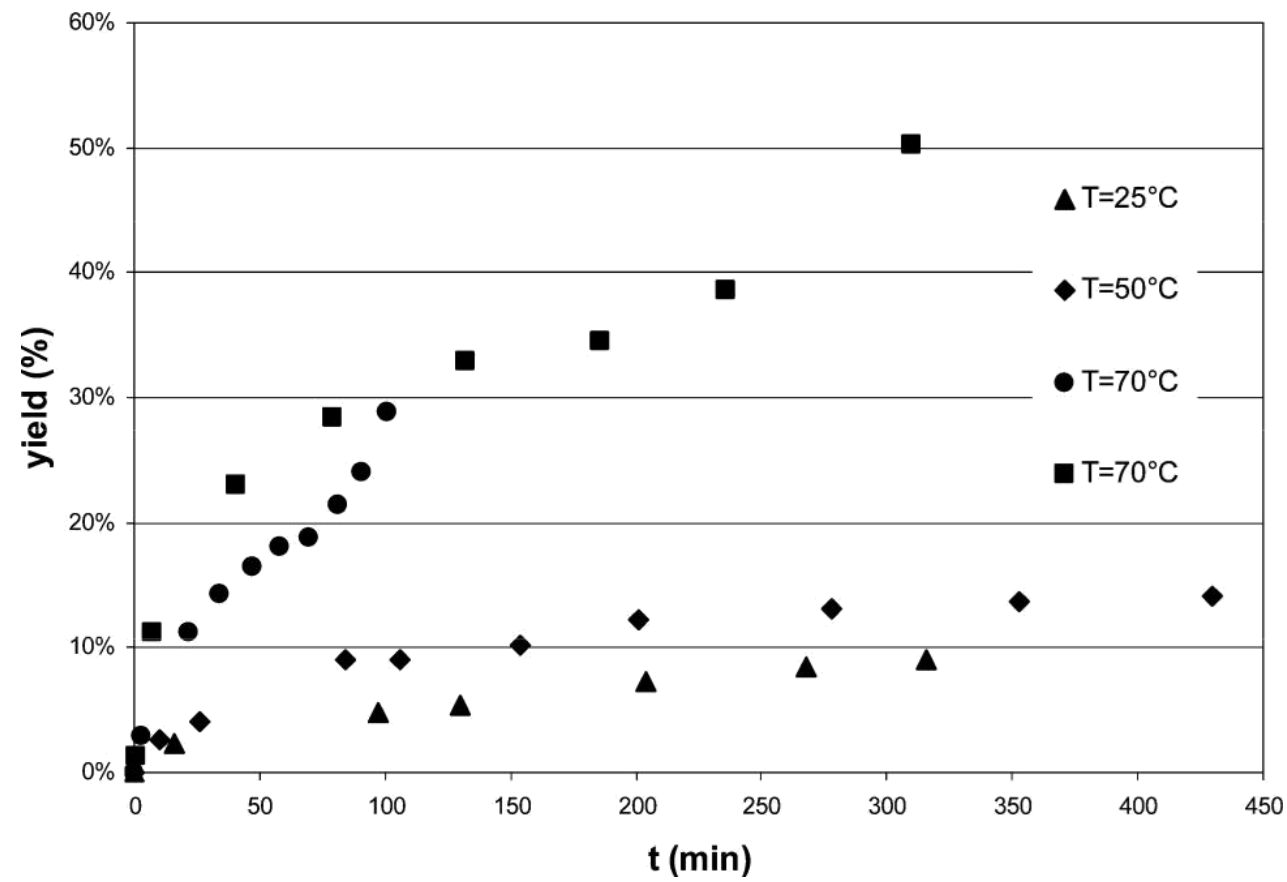

Figure 1. Homopolymerization of MMA with 1/PPh $(1 / 3):[\mathrm{MMA}]=9.3 \mathrm{~mol} \cdot \mathrm{L}^{-1} ; \boldsymbol{\Delta}, \bullet, \bullet:[\mathrm{Ni}]=2.3 \mathrm{mmol} \cdot \mathrm{L}^{-1} ; \mathbf{\square}$ : $[\mathrm{Ni}]=4.6 \mathrm{mmol} \cdot \mathrm{L}^{-1}$.

The number-average molecular weights of the PMMA increased slightly with polymerization temperature from about $M_{\mathrm{n}}=8500 \mathrm{~g} / \mathrm{mol}\left(\mathrm{PDI} \sim 2\right.$ ) at $25^{\circ} \mathrm{C}$ to $\mathrm{Mn}_{\mathrm{n}}=20000 \mathrm{~g} / \mathrm{mol}$ at $50{ }^{\circ} \mathrm{C}$ (PDI $\approx 3$ ) and $\mathrm{Mn}_{\mathrm{n}}=30000 \mathrm{~g} / \mathrm{mol}(\mathrm{PDI} \approx$ 2) at $70{ }^{\circ} \mathrm{C}$ (at $10 \%$ conversion). $M_{n}$ was almost independent of conversion at $25{ }^{\circ} \mathrm{C}$, whereas it first increased until 10-15\% conversion before reaching a plateau at 50 and $70{ }^{\circ} \mathrm{C}\left(M_{n}=26000\right.$ and $37000 \mathrm{~g} / \mathrm{mol}$, respectively). At higher nickel concentration, a decrease in the molecular weights was observed $\left(\mathrm{Mn}_{\mathrm{n}}=7500 \mathrm{~g} / \mathrm{mol}\right.$ at $[\mathrm{Ni}]=4.6$ $\mathrm{mmol} \cdot \mathrm{L}^{-1}$ versus $30000 \mathrm{~g} / \mathrm{mol}$ at $[\mathrm{Ni}]=2.3 \mathrm{mmol} \cdot \mathrm{L}^{-1} ; T=70^{\circ} \mathrm{C} ; \sim 10 \%$ conversion). The synthesized PMMA were moderately syndiotactic (\%rr $=62-66 \%)$. 
Similar experiments were then performed with complex 2. The activation effect of the phosphine was also observed with complex $\mathbf{2}$ but to a lesser extent (Figure 2). Complex $\mathbf{2}$ alone exhibited by itself a significant activity in the homopolymerization of MMA, unlike complex 1 . In both the presence and absence of additional phosphine, the MMA conversions remained low (up to 14\%). The molecular weights of the PMMA were almost independent of conversion and slightly decreased upon heating (from about $M_{\mathrm{n}}=250000 \mathrm{~g} / \mathrm{mol}(\mathrm{PDI} \approx 2.1$ ) at $50{ }^{\circ} \mathrm{C}$ to $M_{\mathrm{n}}=190000 \mathrm{~g} / \mathrm{mol}\left(\mathrm{PDI} \approx 2.1\right.$ ) at $70^{\circ} \mathrm{C}$; at $10 \%$ conversion).

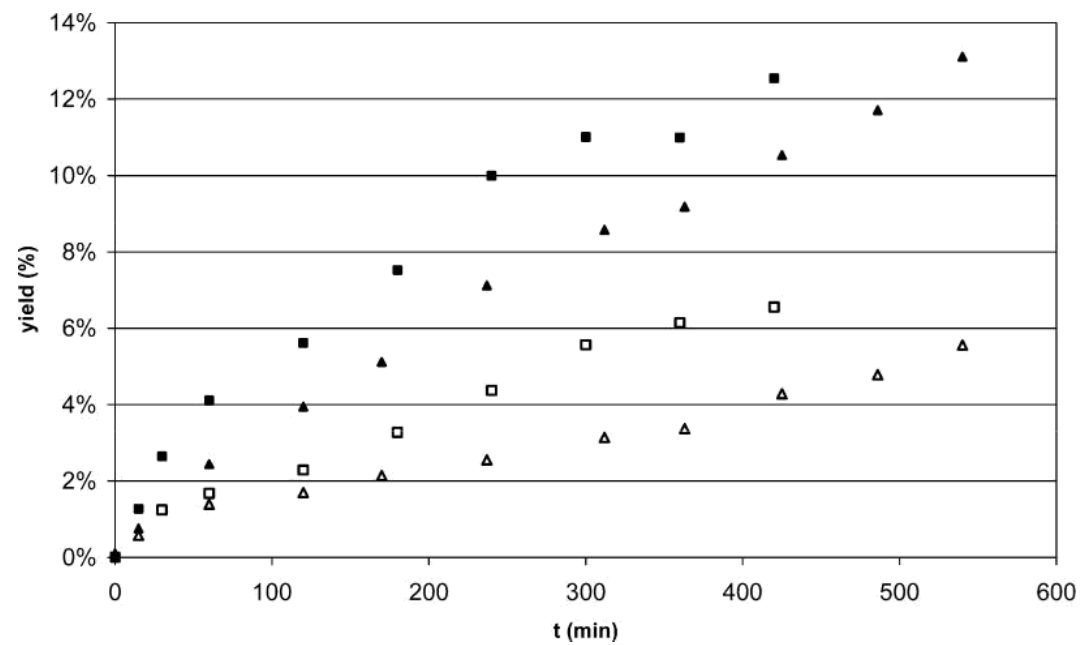

Figure 2. Homopolymerization of MMA with 2: $[\mathrm{MMA}]=9.3 \mathrm{~mol} \cdot \mathrm{L}^{-1} ;[\mathrm{Ni}]=2.3 \mathrm{mmol} \cdot \mathrm{L}^{-1} ; \triangle: T=50^{\circ} \mathrm{C} ; \boldsymbol{\Delta}: T=50$ ${ }^{\circ} \mathrm{C}\left(+3 \mathrm{PPh}_{3}\right) ; \square: T=70{ }^{\circ} \mathrm{C} ; \mathbf{\square}: T=70^{\circ} \mathrm{C}\left(+3 \mathrm{PPh}_{3}\right)$

The results obtained with complexes $\mathbf{1}$ and $\mathbf{2}$ and the "phosphine effect" observed were unexpected. These complexes are known to be active catalysts for the polymerization of nonpolar olefins by classical migratory insertion mechanism in the presence of phosphine scavengers, whereas conversely they require additional phosphine to be active for the homopolymerization of MMA. The activating effect of the phosphine tends to indicate a polymerization mechanism involving the coordination of the phosphine to nickel. Several mechanisms may be considered. Mechanisms based on monomer coordination (migratory insertion or coordinative-anionic addition) would feature a competition for coordination sites between the monomer and the phosphine. Therefore these mechanisms should be disfavored by the presence of additional phosphine. A free radical mechanism based on the homolytic cleavage of the metal-carbon bond may be favored by the presence of additional phoshine, which could act to stabilize the nickel(I) fragment.

The homopolymerization of butyl acrylate (BuA) was also investigated from complexes $\mathbf{1}$ and $\mathbf{2}$ in bulk at $T=50$ and $70{ }^{\circ} \mathrm{C}\left([\mathrm{Ni}]=2.3 \mathrm{mmol} \cdot \mathrm{L}-1\right.$ and $\left.[\mathrm{BuA}]=6.9 \mathrm{~mol} \cdot \mathrm{L}^{-1}\right)$. In the absence of additional $\mathrm{PPh}_{3}$, the conversions achieved were very low ( $<1$ to $2 \%$ after $10 \mathrm{~h}$ ) with both complexes 1 and $\mathbf{2}$. When triphenylphosphine was added to 1 (3 equiv), the formation of poly(butylacrylate) was much more efficient (Figure $\underline{3}$ ) and high-molecular-weight polymers were formed $\left(M_{\mathrm{n}}=135000 \mathrm{~g} / \mathrm{mol}(\mathrm{PDI} \approx 2.4)\right.$ at $50^{\circ} \mathrm{C}$ and $M_{\mathrm{n}}=160000 \mathrm{~g} / \mathrm{mol}(\mathrm{PDI} \approx 2.5)$ at $T=70{ }^{\circ} \mathrm{C}$ at $\sim 7.5$ to $8 \%$ conversion). Complex 2 , however, remained almost inactive when combined with $\mathrm{PPh}_{3}(1.5 \%$ conversion after $10 \mathrm{~h}$ ).

As in the case of MMA polymerization, the enhancing effect of the phosphine was observed for BuA polymerization. Similar hypotheses may be proposed regarding the mechanism of polymerization: free radical versus coordination mechanisms (migratory insertion or anionic). 


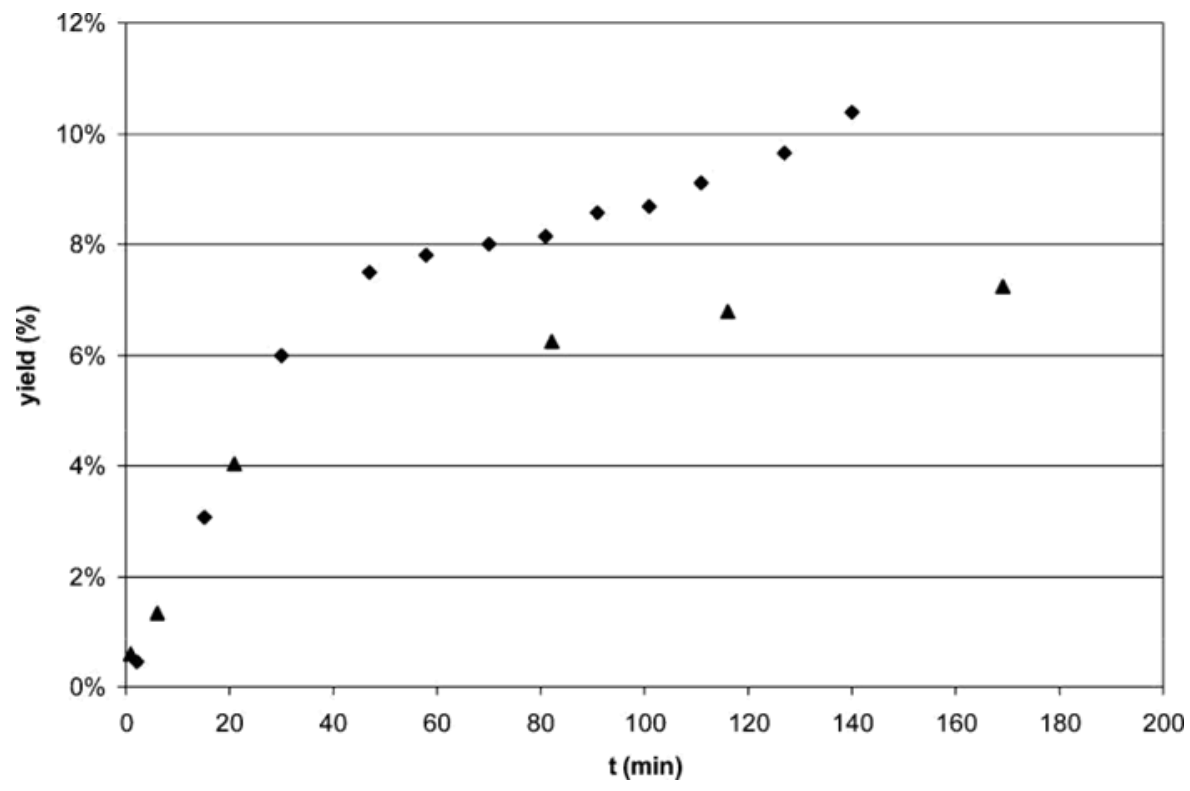

Figure 3. Homopolymerization of BuA with 1/PPh $:[\mathrm{BuA}]=6.9 \mathrm{~mol} \cdot \mathrm{L}^{-1} ;[\mathrm{Ni}]=2.3 \mathrm{mmol} \cdot \mathrm{L}^{-1} ; \boldsymbol{\Delta}: T=50^{\circ} \mathrm{C}(+3$ $\left.\mathrm{PPh}_{3}\right) ; \diamond: T=70{ }^{\circ} \mathrm{C}\left(+3 \mathrm{PPh}_{3}\right)$.

\section{Homo- and Copolymerization of Styrene with (Meth)Acrylates}

To discriminate between the proposed polymerization mechanisms, we performed experiments in the presence of TEMPO as a radical trap. We observed a deactivation of the polymerization of MMA by the addition of TEMPO, but the experiments were not considered to be conclusive. Radical traps have been shown to react with organometallic complexes, which could lead to catalyst deactivation.(10a, 21)

An alternative discrimination method is to investigate copolymerizations and to determine the reactivity ratios. Hence, we investigated the copolymerizations of MMA with BuA and of styrene with these two meth(acrylic) monomers. Styrene is able to (co)polymerize via a radical mechanism or theoretically via migratory insertion, but it cannot copolymerize via coordinative-anionic addition.

The homopolymerization of styrene was first investigated for comparative purposes: in bulk at $T=70{ }^{\circ} \mathrm{C}$ with complexes 1 and 2 with or without additional $\mathrm{PPh}_{3}\left([\mathrm{Ni}]=2.3 \mathrm{mmol} \cdot \mathrm{L}^{-1}\right.$ and $\left.[\mathrm{Sty}]=8.73 \mathrm{~mol} \cdot \mathrm{L}^{-1}\right)$. In all cases, the homopolymerization took place, and the effect of the phosphine was less pronounced than that in the polymerizations of MMA and BuA (after $2 \mathrm{~h}$ of polymerization at $T=70{ }^{\circ} \mathrm{C}$ : $\sim 9 \%$ conversion with 1 vs $\sim 14 \%$ with 1/PPh $(1 / 3) ; \sim 14 \%$ for both systems with 2 ).

The copolymerization of BuA with styrene was studied in bulk with various monomer compositions, with complexes 1 and 2 both in the presence and in the absence of additional $\mathrm{PPh}_{3}\left(T=70^{\circ} \mathrm{C},[\mathrm{Ni}]=2.3 \mathrm{mmol} \cdot \mathrm{L}^{-1}\right)$. The results are summarized in Table $\underline{1}$. Higher copolymer yields were obtained using complex 1 than with complex 2. For both complexes, the yields increased upon addition of the phosphine (a more pronounced effect with 1) and slightly decreased upon addition of BuA. These results are consistent with the homopolymerization results. The composition of the copolymers is not modified by the addition of the phosphine. This tends to indicate that a single mechanism of polymerization is involved in both cases, with an increased concentration of active species in the presence of additional phosphine. 
Table 1. Copolymerization of Styrene and Butyl Acrylate with Complexes 1 and 2a

\begin{tabular}{|c|c|c|c|c|}
\hline $\begin{array}{l}\text { nickel } \\
\text { system }\end{array}$ & $\begin{array}{l}\% \text { wt BuA } \\
\text { feed }\end{array}$ & $\begin{array}{l}\% \text { wt BuA } \\
\text { polymer } \underline{b}\end{array}$ & yield (g) & $\begin{array}{l}\text { reactivity ratios } \\
\text { rBuA/rSty }\left(R^{2}\right) \underline{\mathbf{c}}\end{array}$ \\
\hline \multirow[t]{3}{*}{1} & 20 & 20 & 0.67 & $0.27 / 0.82(1)$ \\
\hline & 50 & 41 & 0.62 & \\
\hline & 70 & 54 & 0.6 & \\
\hline \multirow[t]{3}{*}{$1 / \mathrm{PPh}_{3}(1 / 3)$} & 20 & 20 & 0.83 & $0.24 / 0.81(1)$ \\
\hline & 50 & 40 & 0.87 & \\
\hline & 70 & 54 & 0.8 & \\
\hline \multirow[t]{4}{*}{2} & 20 & 21 & 0.36 & $0.17 / 0.73(0.999)$ \\
\hline & 40 & 35 & 0.33 & \\
\hline & 60 & 44 & 0.26 & \\
\hline & 80 & 58 & 0.22 & \\
\hline \multirow[t]{4}{*}{$2 / \mathrm{PPh}_{3}(1 / 3)$} & 20 & 18 & 0.40 & $0.25 / 0.95$ \\
\hline & 40 & 33 & 0.36 & \\
\hline & 60 & 45 & 0.32 & \\
\hline & 80 & 58 & 0.23 & \\
\hline
\end{tabular}

\footnotetext{
Polymerization conditions: total volume $10 \mathrm{~mL}, T=70^{\circ} \mathrm{C},[\mathrm{Ni}]=2.3 \mathrm{mmol} \cdot \mathrm{L}^{-1}, t=3 \mathrm{~h}$. ${ }^{b}$ Determined by ${ }^{1} \mathrm{H} N M R$.

${ }^{\mathrm{C}} R^{2}=$ coefficient of determination of linear least-squares method.
}

The reactivity ratios of the comonomers were calculated using the Kelen-Tudos method (terminal model) and are reported in Table $\underline{1}$. They are almost identical with both complexes, with or without additional phosphine and close to the reported reactivity ratios for the free radical copolymerization of styrene and butyl acrylate ( $r B u A=0.19, r S t y=0.86) .(22)$ Therefore, the coordinative-anionic mechanism can be excluded. The synthesis of diblock copolymers could theoretically occur via the latter mechanism; however, the calculated reactivity ratios are not in favor of a block structure $(\mathrm{rBuA} \times \mathrm{rSty}=0.12$ to $0.25<1)$. The reactivity ratios also exclude a migratory insertion mechanism that would likely be disfavored by the presence of additional phosphine. In conclusion, the calculated reactivity ratios clearly support a free radical mechanism.

We assume that the radicals are released upon the homolytic cleavage of the metal-carbon bond (Figure $\underline{4}$ a), as has been reported in the literature with palladium complexes.(10) Hence, the nickel complex plays the role of a radical initiator. The homolytic cleavage of the metal-carbon bond may be favored by the addition of the phoshine through a stabilization of the nickel(I) fragment produced (Figure $\underline{4} b$ ). Therefore, adding phosphine would lead to a higher concentration of radicals and as a consequence to a higher activity of the system. 
Moreover, the results indicate that the addition of phosphine does not change the nature of the polymerization mechanism (same reactivity ratios) but reinforces it.

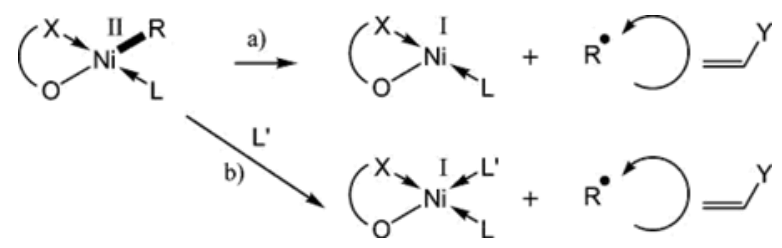

Figure 4. Homopolymerization of a polar vinyl monomer from radicals generated by homolytic cleavage of nickel carbon bond: (a) spontaneous and (b) assisted by phosphine addition $\left(L, L^{\prime}=P P h_{3}, R=P h, X=N\right.$ or $P$ (for salicylaldiminato or phosphinoenolate ligands, respectively)).

Similar investigations were performed with the two other monomer pairs, BuA/MMA and MMA/Sty. Similar effects were observed with respect to yields and copolymer compositions upon the addition of the phosphine to complex $\mathbf{1}$ or $\mathbf{2}$. The reactivity ratios calculated by the Kelen-Tudos method are presented in Table $\underline{2}$.

Table 2. Copolymerization of MMA with Butyl Acrylate or Styrene with Complexes 1 and 2a

\begin{tabular}{|c|c|c|c|c|c|c|}
\hline comonomer $\mathrm{A}$ & comonomer B & nickel system & $r A$ & $r B$ & $\left(R^{2}\right) \underline{\mathbf{b}}$ & rArB \\
\hline \multirow[t]{4}{*}{ MMA $(r A=2.15) \underline{c}$} & $\mathrm{BuA}(r \mathrm{~B}=0.40) \underline{\mathrm{c}}$ & 1 & 0.74 & 0.17 & 1 & 0.13 \\
\hline & & $1 / \mathrm{PPh}_{3}$ & 0.82 & 0.21 & 1 & 0.17 \\
\hline & & 2 & 0.97 & 0.30 & 0.989 & 0.29 \\
\hline & & $2 / \mathrm{PPh}_{3}$ & 1.63 & 0.55 & 0.951 & 0.90 \\
\hline \multirow[t]{4}{*}{ Sty $(r A=0.52) \underline{c}$} & $\mathrm{MMA}(\mathrm{rB}=0.46) \underline{c}$ & 1 & 0.87 & 0.45 & 0.997 & 0.39 \\
\hline & & $1 / \mathrm{PPh}_{3}$ & 0.79 & 0.11 & 0.980 & 0.87 \\
\hline & & 2 & 1.40 & 0.42 & 0.980 & 0.59 \\
\hline & & 2/PPh 3 & 1.06 & 0.39 & 0.980 & 0.41 \\
\hline
\end{tabular}

aPolymerization conditions: total volume $10 \mathrm{~mL}, T=70^{\circ} \mathrm{C},[\mathrm{Ni}]=2.3 \mathrm{mmol} \cdot \mathrm{L}^{-1}, t=3 \mathrm{~h}$.

${ }^{\mathrm{b}} R^{2}=$ coefficient of determination of linear least-squares method.

${ }^{\mathrm{c}}$ From ref 22.

In both cases, the calculated reactivity ratios deviate from those expected for a free radical copolymerization. It seems that the presence of MMA shifts the polymerization mechanism from a pure free radical mechanism toward a more complex mechanism (rBuA $\times$ rMMA $=0.13$ to $0.90<1$ and rSty $\times$ rMMA $=0.39$ to $0.87<1$ compared with 0.86 and 0.24 , respectively, for free radical copolymerization). The simple terminal model used to describe the copolymerization may not be sufficient to describe the copolymerization with MMA. Indeed, the terminal model does not take into account the penultimate effects or the potential coordination of the polar monomers onto the nickel. The coordination of MMA (and potentially of the two other monomers) to the nickel center could be involved in the polymerization mechanism, which would influence the rate of homolytic cleavage of the nickel-carbon bond (as reported for the phosphine, see Figure $\underline{5}$ ). Another explanation for the discrepancy in reactivity ratios could be the coexistence of the free radical mechanism and the coordination/insertion mechanism (Figure $\underline{5}$ ). 


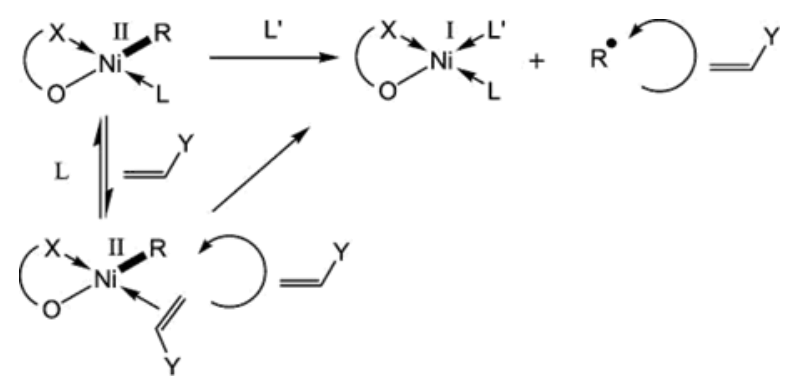

Figure 5. Free radical versus coordination-insertion mechanisms in homopolymerization of the polar vinyl monomers $\left(\mathrm{L}=\mathrm{PPh}_{3}, \mathrm{~L}^{\prime}=\mathrm{PPh}_{3}\right.$ or monomer, $\mathrm{R}=\mathrm{Ph}, \mathrm{X}=\mathrm{N}$ or $\mathrm{P}$ (for salicylaldiminato or phosphinoenolate ligands, respectively)).

On the basis of our results, the nickel complex appears to play a dual role: (1) as a radical initiator whose limited efficiency can be improved by increasing the temperature or adding a Lewis base such as a phosphine and (2) as a classical coordination/insertion catalyst.

The potential of this dual behavior led us to consider the copolymerization of nonpolar olefins (such as ethylene) with polar vinyl monomers. Because these nickel complexes are known catalysts for the polymerization of ethylene by migratory insertion, diblock copolymers of ethylene and polar olefins should be accessible. Moreover, if the homolytic cleavage of the metal-carbon bond can occur reversibly, multiblock copolymers may be accessible. An elegant pathway to the copolymerization of polar and nonpolar olefins using a dual radical/catalytic mechanism can thus be projected (Figure $\underline{6}$ ).

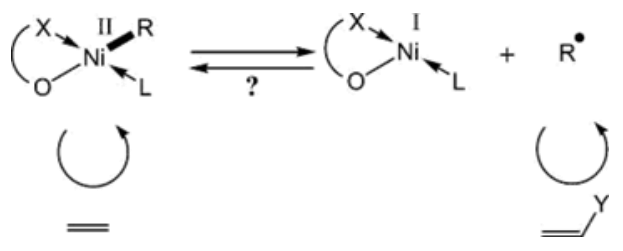

Figure 6. Copolymerization of ethylene and polar vinyl monomers: the dual radical/catalytic pathway.

\section{Copolymerization of (Meth)acrylates and Ethylene}

The copolymerizations of ethylene and MMA or BuA were investigated in bulk ( $50 \mathrm{~mL}$ of polar monomer) using complex 1 at two constant ethylene pressures (25 and 100 bar) without the addition of alkyl aluminum cocatalysts.(23) Under these conditions (even at 100 bar), the polymerization medium was biphasic, with a liquid phase comprising 1 and ethylene in solution in the polar monomer and a second phase comprising mainly supercritical ethylene.(24) The results are presented in Table $\underline{3}$. In bulk polar monomer, polymers were obtained in satisfactory yields but in lower yields than those for the homopolymerization of ethylene.

Under the same conditions, homopolymerizations of ethylene by a migratory insertion mechanism (catalytic polymerization) produced $12 \mathrm{~g}$ of polyethylene from 1 at 100 bar in $50 \mathrm{~mL}$ of toluene versus $6.5 \mathrm{~g}$ of copolymer in $50 \mathrm{~mL}$ of MMA. A decrease in activity was observed upon $\mathrm{PPh}_{3}$ addition to 1 , but $\mathrm{PE}$ properties were unchanged $\left(T_{\mathrm{m}}=124.0^{\circ} \mathrm{C}\right.$ from 1 and $T_{\mathrm{m}}=123.2^{\circ} \mathrm{C}$ from 1/PPh $)$. Note that the low melting points of the PE obtained with 1 or $1 / \mathrm{PPh}_{3}$ are due to the "chain walking" mechanism,(14a) which leads to a branched polymer. Under these conditions (at 100 bar, using an AIBN concentration identical to the concentration of nickel complex 1), only traces of low-molecular-weight polyethylene are produced by free radical homopolymerization of ethylene. Under similar conditions, the copolymerization of a polar monomer (MMA or BuA) and ethylene using higher concentrations of AIBN ( $\times 3$ ) led to amorphous copolymers enriched in the polar monomer ( $94 \mathrm{~mol} \%$ MMA for E/MMA copolymer and $83 \mathrm{~mol} \%$ BuA for E/BuA copolymer).

The polymer obtained by the copolymerization of ethylene and MMA at 25 bar using 1 as catalyst contained 20.5 mol \% MMA, whereas at 100 bar the MMA content dropped to $2.7 \mathrm{~mol} \%$. These two polymers, respectively, melt at 112 and $122^{\circ} \mathrm{C}$. When phosphine was added, the yields decreased and the incorporation of MMA in the copolymer increased to, respectively, $34 \mathrm{~mol} \%$ at 25 bar and $7.7 \mathrm{~mol} \%$ at 100 bar. The first polymer is amorphous, whereas the second exhibits a weak broad melting transition $\left(T_{\mathrm{m}}=110-121^{\circ} \mathrm{C}\right)$. No glass transition 
was observed between $-100{ }^{\circ} \mathrm{C}$ and $+150{ }^{\circ} \mathrm{C}$, even in the case of the amorphous polymer. The $T_{\mathrm{g}}$ of long MMA sequences potentially present (PMMA or long MMA sequences) can be expected at $\sim+100{ }^{\circ} \mathrm{C}$, which overlaps with the temperature range for melting of the PE sequences (PE or long ethylene sequences).

The molecular weights of the polymers were one order of magnitude lower than in the case of the homopolymerization of MMA and in the same range as for homopolyethylenes (obtained using 1 under similar conditions).

In the case of BuA, no activity was observed at 25 bar with 1 only, whereas phosphine addition led to the formation of an amorphous polymer containing $86.3 \mathrm{~mol} \%$ of BuA. The molecular weight of the polymer was lower than that of the corresponding homopolymer of BuA obtained using $1 / \mathrm{PPh}_{3}$. The glass transition of polymer was observed at $-49^{\circ} \mathrm{C}$, indicative of long BuA sequences $\left(\mathrm{Tg}\right.$ (homoPBuA) $\left.=-54^{\circ} \mathrm{C}\right)$.

Table 3. Copolymerization of MMA and Butyl Acrylate with Ethylene from Complex 1a

\begin{tabular}{|c|c|c|c|c|c|c|}
\hline $\begin{array}{l}\text { polar monomer } \\
\text { (PM) }\end{array}$ & nickel system & $\begin{array}{l}\text { ethylene } \\
\text { pressure }\end{array}$ & $\begin{array}{l}\text { yield } \\
\text { (g) }\end{array}$ & $\begin{array}{l}M \mathrm{n}(\mathrm{PDI}) \\
\mathrm{g} / \mathrm{mol}\end{array}$ & $\begin{array}{l}\text { \% PM } \\
\text { polymerc }\end{array}$ & $T_{\mathrm{m}}\left({ }^{\circ} \mathrm{C}\right)$ \\
\hline \multirow[t]{4}{*}{ MMA } & 1 & 25 & 4.1 & $10000(3.0)$ & 20.5 & 112.3 \\
\hline & 1 & 100 & 6.5 & 12000 (3.7) & 2.7 & 122.4 \\
\hline & $1 / \mathrm{PPh}_{3}$ & 25 & 3.1 & $28100(1.7)$ & 34.0 & no $T_{m}$ \\
\hline & 1/PPh 3 & 100 & 1.2 & 37600 (1.9) & 7.7 & 110-121 \\
\hline \multirow[t]{2}{*}{ BuA $\underline{b}$} & 1 & 25 & & & & \\
\hline & 1/PPh 3 & 25 & 2.2 & $58000(5.2)$ & 86.3 & no $T_{\mathrm{m}}$ \\
\hline
\end{tabular}

a Polymerization conditions: $50 \mathrm{~mL}$ of polar monomer $(\mathrm{PM}), T=50^{\circ} \mathrm{C},[\mathrm{Ni}]=2.3 \mathrm{mmol} \cdot \mathrm{L}^{-1}, t=2 \mathrm{~h}$.

${ }^{\mathrm{b}} t=4 \mathrm{~h}$.

${ }^{\mathrm{c}} \mathrm{mol} \%$, determined by ${ }^{1} \mathrm{H} \mathrm{NMR}$.

Even though MMA incorporation in the polymers was measured by ${ }^{1} \mathrm{H} N M R$, the structure of the polymers formed with 1 and 1/PPh 3 is not yet clear. In particular, the presence of homopolymers of ethylene, of MMA (or of MMA enriched copolymers from a pure free radical mechanism), or both together with block copolymers cannot be ruled out. The polymer properties can help to characterize the nature of these polymers. The fully amorphous polymer obtained from $1 / \mathrm{PPh}_{3}$ at 25 bar was found to contain $66 \%$ of ethylene. The absence of a melting transition for this polymer, however, suggests the absence of long ethylene sequences (homopolyethylene or polyethylene-block) and therefore indicates the presence of a copolymer structure.

Further characterization of the polymers was undertaken by extraction of the polymers with boiling MEK. (See Table 4 for E/MMA copolymers.) Because homoPMMA (and homoPBuA) are fully soluble in boiling MEK and homoPE (branched and synthesized with 1 or $1 / \mathrm{PPh}_{3}$ ) is insoluble, the extraction can help in determining the presence of homopolymers. The chemical composition of the two fractions of polymer (soluble and insoluble in MEK) was analyzed by ${ }^{1} \mathrm{H}$ NMR. 
Table 4. MEK Extractions of E/MMA copolymers Obtained from 1a

\begin{tabular}{|c|c|c|}
\hline polymers (E/MMA) $\underline{b}$ & $\begin{array}{l}\text { wt \% soluble in MEK (MMA } \\
\text { content mol \%)도 }\end{array}$ & $\begin{array}{l}\text { wt \% insoluble in MEK } \\
(\text { MMA content mol \%)드. }\end{array}$ \\
\hline homo PMMA (0/100) & 100 & 0 \\
\hline homo PE (100/0) & 0 & 100 \\
\hline copolymer (79.5/20.5) & $32(30)$ & $68(16)$ \\
\hline copolymer (97.3/2.7) & $6(40)$ & $94(0.5)$ \\
\hline copolymer (66/34) & $100(34)$ & $0(0)$ \\
\hline copolymer (92.3/7.7) & $66(11)$ & $34(1)$ \\
\hline
\end{tabular}

${ }^{a}$ Extractions conditions: $2 \mathrm{~h}$ in boiling MEK.

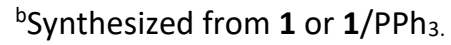

${ }^{\mathrm{c}}$ Determined by ${ }^{1} \mathrm{H}$ NMR.

In the case of the ethylene/BuA copolymerization ( $86.3 \mathrm{~mol} \% \mathrm{BuA})$, the polymer obtained is amorphous and fully soluble in MEK. This indicates the absence of polyethylene.

In the case of the crystalline polymer containing $20.5 \mathrm{~mol} \% \mathrm{MMA}$, both fractions contain high levels of MMA inclusion ( $30 \mathrm{~mol} \% \mathrm{MMA}$ in the MEK soluble fraction and $16 \mathrm{~mol} \%$ in the MEK insoluble one) while being composed mainly of ethylene units (70 and $84 \mathrm{~mol} \%$, respectively). Because the MEK soluble fraction cannot contain PE and the MEK insoluble fraction cannot contain PMMA, this indicates that copolymers were produced. Nevertheless, the presence of polyethylene in the MEK insoluble fraction and of PMMA in the MEK soluble fraction cannot be ruled out. Hence, the polymer produced using $\mathbf{1}$ can be characterized as a mixture of polymers, probably containing diblock or potentially multiblock copolymers with a variety of block lengths. In the case of the crystalline polymer containing $2.7 \mathrm{~mol} \% \mathrm{MMA}$, a mixture of ethylene-enriched (close to homopolyethylene containing 99.5 mol \% of ethylene units) and MMA-enriched (40 mol \%) copolymers was determined. The same trends are observed with the polymer containing $92 \mathrm{~mol} \%$ of ethylene with different ratios between MEK soluble and insoluble fractions (corresponding to a mixture of 34 wt \% of an ethylene enriched copolymer and $66 \mathrm{wt} \%$ of copolymer containing $11 \mathrm{~mol} \% \mathrm{MMA}$ ). Finally, in the case of the amorphous polymer (34 mol \% MMA), the absence of homopolyethylene was confirmed by the presence of only an MEK soluble fraction.

In conclusion, the MEK extractions indicate the formation of copolymers. Additionally, the formation of homopolymers appears to be limited or absent altogether. The complex mixture of copolymers obtained is consistent with the proposed dual catalytic/radical mechanism. Such a mechanism would indeed generate block copolymers with a chemical composition distribution (CCD, with respect to the comonomer levels and the block lengths). The CCD would then be determined by the equilibrium between the different nickel species, $\mathrm{Ni}$ (II) versus $\mathrm{Ni}(\mathrm{I})$, that is, catalytically active nickel for the polymerization of olefins versus radical initiating nickel for the polymerization of polar monomers. On the basis of the results of this study, the latter equilibrium is apparently displaced toward the release of radicals upon the addition of phosphine (which was demonstrated to promote the radical formation in the homo- and copolymerization of (meth)acrylates and styrene) and at low ethylene concentration (pressure). Higher ethylene pressures appear to displace the equilibrium toward the catalytically active species, resulting in ethylene-enriched copolymers.

Further characterization of the polymers was performed by ${ }^{13} \mathrm{C} N \mathrm{NM}$ analysis. The presence of a mixture of copolymers prevented detailed quantitative analyses, but a number of conclusions could be drawn. The sequences of polar monomer (including identification of the tacticity of the MMA block) and of ethylene 
(branched ethylene block due to chain-walking mechanism) were identified on the ${ }^{13} \mathrm{C}$ NMR spectra. Additional new weak signals were observed in the case of MMA-enriched copolymers obtained at 25 bar, which may arise from the alternating E/MMA units and are present in both MEK soluble and insoluble fractions. These signals were absent from the spectra of ethylene-enriched copolymers obtained at 100 bar.

Copolymers with complex structures were obtained from the copolymerization of ethylene and polar monomer using complex 1 . The high copolymerization yields are significantly different from the yields expected from both a pure free radical polymerization and a pure coordination/insertion polymerization. Under the pressure and temperature conditions used, radical polymerization is inefficient, and coordination/insertion polymerization is inhibited by the presence of the polar monomer. The copolymers synthesized are not statistical and differ from MMA-enriched copolymers produced by a free radical mechanism. They instead exhibit a rather blocky character.

These results are consistent with the proposed polymerization mechanism involving both coordination/insertion and free radical mechanisms. This mechanism is based on the proposed dual role of the nickel complex, as a catalyst (by migratory insertion into the $\mathrm{Ni}{ }^{\prime \prime}-\mathrm{C}$ bond) and as a radical initiator (by homolytic cleavage of the $\mathrm{Ni}^{\prime \prime}-$ $C$ bond), as illustrated in Figure $\underline{6}$. The efficiency of the radical initiation can be improved by the addition of phosphine. In the case of the BuA/E copolymerization, the addition of phosphine is even necessary to promote the polymerization.

The proposed mechanism-shuttling between coordination/insertion and radical polymerization still needs to be confirmed. Furthermore, reversible homolytic cleavage of the metal-carbon bond could provide access to the synthesis of multiblock copolymers of polar and nonpolar olefins. The term "reversible homolytic cleavage of the metal-carbon bond" refers to the equilibrium between the $\mathrm{Ni}(\mathrm{I})$ and $\mathrm{Ni}(\mathrm{II})$ species upon reoxidation of the $\mathrm{Ni}(\mathrm{I})$ species by addition of, for example, a propagating macroradical. Whereas the existence of such mechanismshuttling still needs to be proven, the permanent consumption of ethylene during the polymerization and properties of the copolymers indicate that multiblocks copolymers of ethylene and polar monomers are formed.

\section{Conclusions}

The homopolymerizations of butylacrylate (BuA) and methylmethacrylate (MMA) (and styrene) were investigated in bulk with two neutral nickel olefin polymerization catalysts: the nickel(II) salicylaldiminato complex 1 and the nickel(II) phosphinoenolate complex $\mathbf{2}$. Homopolymerization was found to be enhanced by heating and upon addition of triphenylphosphine, contrary to what is expected for the "classical" polymerization of olefins with these nickel complexes (which require phosphine scavengers).

The copolymerizations of BuA, MMA, and styrene indicated the involvement of a free radical mechanism initiated by complexes $\mathbf{1}$ and $\mathbf{2}$, as demonstrated by the calculations of the comonomer reactivity ratios.

The dual role of the nickel complexes in the copolymerization was highlighted. On one hand, the nickel complexes act as classical catalysts for the polymerization of olefins (coordination-insertion mechanism). On the other hand, the nickel complexes act as radical initiators, due to the homolytic cleavage of the nickel-carbon bond. The addition of triphenylphosphine appears to promote the homolytic cleavage.

On the basis of this feature of the nickel complexes, an original dual radical/catalytic pathway was postulated for the copolymerization of ethylene with polar monomers (e.g., MMA and BuA) by complex 1. High copolymer yields were obtained. The addition of triphenylphosphine to complex 1 enhanced the rate of the copolymerization of ethylene and MMA, whereas its presence was necessary for the E/BuA copolymerization to proceed. Mixtures of copolymers were obtained, ranging from ethylene-enriched copolymers to polar monomerenriched copolymers. The copolymers synthesized were found to exhibit a blocky microstructure, as demonstrated by thermal analysis, extraction in boiling MEK, and NMR analysis. The successful synthesis of $E / M M A$ and $E / B u A$ copolymers confirmed the potential dual role of the nickel complexes as a catalyst and radical initiator. The ethylene and polar monomer blocks are thought to be produced via a coordination/insertion mechanism and a free radical mechanism, respectively. The efficiency of the free radical mechanism seems to be improved by the addition of phosphine. The proposed mechanism shuttling between coordination/insertion and radical polymerization requires further study for confirmation. The shuttling would be facilitated by the reversibility of the homolytic cleavage of the metal-carbon bond and would give access to multiblock copolymers of polar and nonpolar olefins. Further investigations are in progress into the proposed dual radical/catalytic mechanism and the characterization of the copolymers synthesized (using HT-LC techniques and ${ }^{13} \mathrm{C} \mathrm{NMR}$ ). 


\section{Acknowledgment}

Financial support by Arkema is gratefully acknowledged. E.G. thanks the "Ministère de la Recherche et de l'Enseignement Supérieur" for fellowship.

\section{References}

1. (a) Baskaram, D.; Müller, A. H. E. Prog. Polym. Sci. 2007, 32, 173 (b) Baskaram, D. Prog. Polym. Sci. 2003, 28, 521(c) Beylen, M. V.; Bywater, S.; Smets, G.; Szwarc, M.; Worsfold, D. J. Adv. Polym. Sci. 1988, 86, 87

2. (a) Debuigne, A.; Poli, R.; Jérôme, C.; Jérôme, R.; Detrembleur, C. Prog. Polym. Sci. 2009, 34, 211 (b) Yamago, S. Chem. Rev. 2009, 109, 5041(c) Ouchi, M.; Terashima, T.; Sawamoto, M. Chem. Rev. 2009, 109, 5157(d) Braunecker, W. A.; Matyjaszewski, K. Prog. Polym. Sci. 2007, 32, 93 (e) Di Lena, F.; Matyjaszewski, K. Prog. Polym. Sci. 2010, 35, 959

3. Chen, E. Y.-X. Chem. Rev. 2009, 109, 5157

4. Yasuda, H.; Yamamoto, H.; Yokota, K.; Miyake, S.; Nakamura, A. J. Am. Chem. Soc. 1992, 114, 4908

5. Collins, S.; Ward, S. G. J. Am. Chem. Soc. 1992, 114, 5460

6. Fullana, M. J.; Miri, M. J.; Vadhavkar, S. S.; Kolhatkar, N.; Delis, A. C. J. Polym. Sci., Part A: Polym. Chem. 2008, 46, 5542

7. (a) Endo, K.; Inukai, A.; Otsu, T. Macromol. Rapid Commun. 1994, 15, 893 (b) Coutinho, F. M. B.; Costa, M. A. S.; Monteiro, L. F.; de Santa Maria, L. C. Polym. Bull. 1997, 38, 303 (c) Endo, K. Macromol. Chem. Phys. 1999, 200, 1722 (d) Endo, K.; Inukai, A. Polym. Int. 2000, 49, 110

8. (a) Carlini, C.; Martinelli, M.; Passaglia, E.; Galletti, A. M. R.; Sbrana, G. Macromol. Rapid Commun. 2001, 22, 664 (b) Carlini, C.; Martinelli, M.; Galletti, A. M. R.; Sbrana, G. J. Polym. Sci., Part A: Polym. Chem. 2003, 41, 1716 (c) Carlini, C.; Martinelli, M.; Galletti, A. M. R.; Sbrana, G. J. Polym. Sci., Part A: Polym. Chem. 2003, 41, 2117

9. (a) Li, X.-F.; Li, Y.-G.; Li, Y.-S.; Chen, Y.-X.; Hu, N.-H. Organometallics 2005, 24, 2502 (b) He, X.; Wu, Q. Appl. Organomet. Chem. 2006, 20, 264

10. (a) Tian, G.; Boone, H. W.; Novak, B. Macromolecules 2001, 34, 7656 (b) Elia, C.; Elyashiv-Barad, S.; Sen, A.; Lopez-Fernandez, R.; Albeniz, A. C.; Espinet, P. Organometallics 2002, 21, 4249 (c) Albeniz, A. C.; Espinet, P.; Lopez-Fernandez, R. Organometallics 2003, 22, 4206 (d) Nagel, M.; Sen, A. Organometallics 2006, 25, 1722 (e) Albeniz, A. C.; Espinet, P.; Lopez-Fernandez, R. J. Polym. Sci., Part A: Polym. Chem. 2006, 44, 5682 (f) Szuromi, E.; Shen, H.; Goodall, B. L.; Jordan, R. F. Organometallics 2008, 27, 402 (g) Lopez-Fernandez, R.; Carrera, N.; Albeniz, A. C.; Espinet, P. Organometallics 2009, 28, 4996

11. (a) Stibrany, R. T.; Schulz, D. N.; Kacker, S.; Patil, A. O.; Baugh, L. S.; Rucker, S. P.; Zushma, S.; Berluche, E.; Sissano, J. A. Macromolecules 2003, 36, 8584 (b) Baugh, L. S.; Sissano, J. A.; Kacker, S.; Berluche, E.; Stibrany, R. T.; Schulz, D. N.; Rucker, S. P. J. Polym. Sci., Part A: Polym. Chem. 2006, 44, 1817 (c) Galletti, A. M. R.; Carlini, C.; Giaiacopi, S.; Martinelli, M.; Sbrana, G. J. Polym. Sci., Part A: Polym. Chem. 2007, 45, 1134

12. (a) Wu, B.; Lenz, R. W.; Hazer, B. Macromolecules 1999, 32, 6856 (b) Olson, J. A.; Boyd, R.; Quail, J. W.; Foley, S. R. Organometallics 2008, 27, 5333 (c) Po, R.; Fiocca, L.; Cardi, N.; Simone, F.; Cardaci, M. A.; Spera, S.; Salvalaggio, M. Polym. Bull. 2006, 56, 101

13. (a) Guironnet, D.; Roesle, P.; Runzi, T.; Göttker-Schnetmann, I.; Mecking, S. J. Am. Chem. Soc. 2009, 131, 422 (b) Guironnet, D.; Caporaso, L.; Neuwald, B.; Göttker-Schnetmann, I.; Cavallo, L.; Mecking, S. J. Am. Chem. Soc. 2010, 132, 4418 (c) Runzi, T.; Guironnet, D.; Göttker-Schnetmann, I.; Mecking, S. J. Am. Chem. Soc. 2010, 132, 16623

14. (a) Ittel, S. D.; Johnson, L. K.; Brookhart, M. Chem. Rev. 2000, 100, 1169 (b) Boffa, L. S.; Novak, B. M. Chem. Rev. 2000, 100, 1479 (c) Berkefeld, A.; Mecking, S. Angew. Chem., Int. Ed. 2008, 47, 2538(d) Nakamura, A.; Ito, S.; Nozaki, K. Chem. Rev. 2009, 109, 5215

15. Salicylaldiminato nickel(II) complexes: (a) Johnson, L. K.; Bennett, A. M. A.; Ittel, S. D.; Wang, L.; Parthasarathy, A.; Hauptman, E.; Simpson, R. D.; Feldman, J.; Coughlin, E. B.WO 98/30609, 1998. (b) Wang, C.; Friedrich, S.; Younkin, T. R.; Li, R. T.; Grubbs, R. H.; Bansleben, D. A.; Day, M. W. Organometallics 1998, 17, 3149

(c) Younkin, T. R.; Connor, E. F.; Henderson, J. I.; Friedrich, S. K.; Grubbs, R. H.; Bansleben, D. A. Science 2000, 287, 460

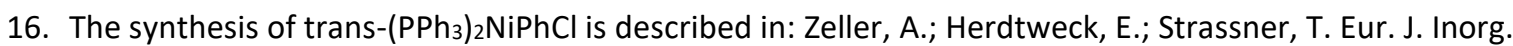
Chem. 2003, 1802

17. (a) Bauers, F. M.; Mecking, S. Macromolecules 2001, 34, 1165 (b) Mecking, S.; Monteil, V.; Huber, J.; Kolb, L.; Wehrmann, P. Macromol. Symp. 2006, 236, 117

18. Hamper, B. C. J. Org. Chem. 1988, 53, 5558 
19. (P,O) nickel(II) complexes: (a) Keim, W.; Kowaldt, F. H.; Goddard, R.; Krueger, C. Angew. Chem., Int. Ed. 1978, 17, 466 (b) Ostaja-Starzewski, K. A.; Witte, J. Angew. Chem., Int. Ed. 1985, 24, 599 (c) Klabunde, U.; Ittel, S. D. J. Mol. Catal. 1987, 41, 123 (d) Klabunde, U.; Mulhaupt, R.; Herskovitch, T.; Janowicz, A. H.; Calabrese, J.; Ittel, S. D. J. Polym. Sci., A: Polym. Chem. 1987, 25, 1989 (e) Kuhn, P.; Semeril, D.; Jeunesse, C.; Matt, D.; Neuburger, M.; Mota, A. Chem.-Eur. J. 2006, 12, 5210

20. (a) Waltman, A. W.; Younkin, T. R.; Grubbs, R. H. Organometallics 2004, 23, 5121 (b) Berkefeld, A.; Drexler, M.; Möller, H. M.; Mecking, S. J. Am. Chem. Soc. 2009, 131, 12613

21. Nagel, M.; Paxton, W. F.; Sen, A.; Zakharov, L.; Rheingold, A. L. Macromolecules 2004, 37, 9305

22. (a) Beuermann, S.; Buback, M. Prog. Polym. Sci. 2002, 27, 191 (b) Fernandez-Garcia, M.; Fernandez-Sanz, M.; Madruga, E. L.; Fernandez-Monreal, M. C. Macromol. Chem. Phys. 1999, 200, 199

23. Navarro, C.; Leblanc, A.; Monteil, V.; Spitz, R.; Boisson, C.; Broyer, J. P.WO 2010/049633 A1, 2010.

24. Grau, E.; Broyer, J. P.; Boisson, C.; Spitz, R.; Monteil, V. Phys. Chem. Chem. Phys. 2010, 12, 1166 